\title{
A Student Society Bridges the Gap between Interest and Involvement in the NICU by Creating a Cuddler Guide and Program
}

\begin{abstract}
Balton $\mathrm{K}^{1}$, Saad $\mathrm{P}^{1}$, Salazar $\mathrm{I}^{1}$, Restivo $\mathrm{J}^{2}$ and Desport BC ${ }^{3 *}$

${ }^{1}$ Occupational Therapy Program Graduates of SUNY Downstate Health Sciences University, NY, USA

${ }^{2}$ National Perinatal Association Board Member, Director of NPASS Outreach, SUNY Downstate Health Sciences University, Occupational Therapist, New YorkPresbyterian Brooklyn Methodist Hospital, USA

${ }^{3}$ Associate Dean for Strategic Initiatives and Associate Professor, Occupational Therapy Program at SUNY Downstate Health Sciences University, NY, USA

*Corresponding author: Brigitte C Desport, Associate Dean for Strategic Initiatives and Associate Professor, Occupational Therapy Program at SUNY Downstate Health Sciences University, 450 Clarkson Avenue, MSC 94, Brooklyn, NY 11203, USA
\end{abstract}

Received: J une 23, 2021; Accepted: August 04, 2021; Published: August 11, 2021

\section{Introduction}

A group of occupational therapy students, who serve as executive board members of the National Perinatal Association Student Society (NPASS) chapter at The State University of New York (SUNY) Downstate Health Sciences University created a Cuddler Guide and Program. They worked with National Perinatal Association (NPA) Board Members Jessica Restivo, MS, OTR/L and Brigitte Desport DPS, OTR/L, BCP, ATP on these projects to contribute to the welfare and development of babies in the Neonatal Intensive Care Unit (NICU). To understand how this NPASS chapter embarked on such an initiative, below outlines the student organization's connection to its parent organization (National Perinatal Association), its development and experiences, and finally the creation of the Cuddler Guide and Program.

\section{The National Organization: NPA}

The National Perinatal Association (NPA) is a national organization with a diverse membership of healthcare and service providers, parents and caregivers, educators, and students who are interested in perinatal care. NPA's mission is to educate, advocate, and integrate, with a shared purpose to: promote evidence-based practice in perinatal care; partner with community members who require the most support; and facilitate interdisciplinary collaboration so that all benefit from the evidence of the various professions represented [1].

\section{The Student Organization: NPASS}

One of the hallmarks of NPA's mission is to educate. This involves enhancing student engagement, learning and opportunities in perinatal care. To better structure these initiatives and demonstrate its commitment to growing a strong community, the National Perinatal Association Student Society was created in 2016 by then medical student, Cody Miller. This first chapter, born out of Baylor University, Houston, TX, consisted of medical and physician assistant students.

The second chapter, established at SUNY Downstate Health Sciences University in Brooklyn, NY, was created in 2017 by then occupational therapy student, Jessica Restivo. SUNY Downstate's NPASS Chapter is the most interdisciplinary chapter comprised of students from the various health professions within this academic institution. A third chapter was formed with the Occupational Therapy Program at Salus University in 2021. NPA plans to continue expanding and forming additional NPASS chapters at academic institutions where students are passionate about perinatal care and interested in connecting with the organization.

NPASS gives students of varying disciplines a voice to guide their learning. NPASS welcomes all students who are committed to interdisciplinary education, scholarship, advocacy, and service related to perinatal health. In order to bridge the gap between interest and involvement in the NICU we believe that students benefit from exposure to this specialized area of practice. From an occupational therapy perspective, NPASS strives to offer students who wish to pursue a career as a neonatal therapist with a foundation and framework for success. Members of NPASS are supported by faculty advisors and guided by NPA Board Members and the Director of NPASS Outreach. NPASS thrives from the passion and innovation of its students. Students learn the roles of an interdisciplinary team and how the disciplines collaborate with one another, gain hands on experience, engage in mentorship, initiate new programs, advocate for best practice, and create events to address community needs.

\section{How to Start an NPASS Chapter at Your Institution}

Any interested student or faculty member can start an NPASS Chapter at their institution. This process is structured and fully supported by NPA's Board Member and Director of NPASS Outreach, Jessica Restivo. All new presidents are provided with the framework to start a chapter and will communicate frequently with Ms. Restivo for support. Students hoping for exposure to perinatal care and the NICU, may want to consider expanding their student experience by starting a chapter of NPASS at their institution.

To start an NPASS chapter at SUNY Downstate, Jessica Restivo, and the chapter's first President, sought approval from the Department of Student Life and Services. A requirement of starting a student organization is there has to be at least one faculty advisor. Ms. Restivo was fortunate to have access to two
Phys Med Rehabil Int - Volume 8 Issue 3 - 2021

ISSN : 2471-0377 | www.austinpublishing group.com

Desport et al. (C) All rights are reserved
Citation: Balton K, Saad P, Salazar I, Restivo J and Desport BC. A Student Society Bridges the Gap between Interest and Involvement in the NICU by Creating a Cuddler Guide and Program. Phys Med Rehabil Int. 2021; 8(3): 1185. 
NPA Board members - Brigitte C. Desport, Associate Dean for Strategic Initiatives and Associate Professor in the OT Program and Maryanne F. Laffin, Clinical Assistant Professor in the Midwifery Program, both from the School of Health Professions - to serve as faculty advisors. Next, elections were held welcoming students from programs such as occupational therapy, midwifery, physical therapy, medical school, physician assistant, nursing, public health, and other health professions to fill board positions. All NPASS Chapters are governed by the Constitution established by the first chapter. These bylaws set standards to elect Executive Board positions such as Vice President, Secretary, Treasurer, Community Service, Research \& Scholarship, Social Media, Mentorship, and Education and Outreach. Students who are interested in perinatal care but may not want to fulfill a leadership role can join NPASS as a student member. SUNY Downstate's NPASS chapter has held events advocating for Breastfeeding Awareness Month, the March of Dimes Walk, World Prematurity Day, and Kangaroo Care Day. Members have created newsletters for publication through NPA and have had the opportunity to collaborate with clinicians to work on projects and publications. Through NPASS, members are empowered to initiate programs and develop connections with mentors to develop their clinical skills prior to graduation.

\section{NICU Cuddller Guide and Program}

During the 2019-2020 academic year, it was the mission of the NPASS Executive Board at SUNY Downstate to give occupational therapy students the opportunity to gain experience in perinatal care. Students wanted to learn the role of OTs in the NICU, extending the content covered in the program's pediatric curriculum which focused on early intervention, inpatient rehabilitation, and schoolbased practice. NPASS established a partnership with Kings County Hospital Center to address their overwhelming interest and the limited opportunities for hands-on learning in this critical setting. Kings County Hospital is a Level One Trauma and Level 3 NICU Center located across the street from SUNY Downstate. This convenient location offered students the flexibility to participate in observations and mentorships between classes.

During their time in the NICU, students attended medical rounds, observed members of the team, and learned about professionalism. Participating in rounds gave students the opportunity to attain education targeting the medical complexities of NICU infants. The student's volunteer experience was similar to that of a level one fieldwork placement which is primarily observations. They observed a neonatal occupational therapist treat infants on her caseload. After witnessing the impact OTs have in the NICU, students learned the significance of providing both positive interaction and supportive touch to neonates. One student reflected on their experience, stating, "Having exposure to NICU care was one of the most fruitful experiences in my time as student. I was able to learn about how occupational therapy can help medically fragile infants, and witness that there are so many more babies in need of our support".

Traditionally, hospitals have cuddling programs where the role of a cuddler is to hold babies in the NICU when the parents are unable to do so. Although several hospitals have cuddler programs with volunteers, NPASS sought to recruit students interested in neonatology as cuddlers. This led to the idea of starting a cuddler program at Kings
County Hospital that was slated to begin with a student cuddling training provided by NPASS faculty advisors. Unfortunately, this training coincided with the onset of closures due to the COVID-19 pandemic, including the transition to distance learning, prohibition of on campus activities, and the strict restrictions put in place across hospital settings. This halted the launch of the cuddle program and caused students to deliberate over other options to bring it to fruition.

In the spirit of the adaptive nature of OTs, Isabel Salazar, Katherine Balton, Siham Bennis, Ariane Mallon, and Pascale Saad, then occupational therapy students and members of the SUNY Downstate's NPASS chapter collaborated with NPA Board Members Jessica Restivo, Brigitte Desport, and Jenene Craig to create A NICU Cuddler Guide to Support Neuroprotection. This educational resource aims to support volunteers and outlines how to cuddle infants in hospitals. Future NPASS objectives include establishing the cuddler program at Kings County Hospital and sharing this guide with other hospitals that may want to train their volunteers in neuroprotection. A NICU Cuddler Guide to Support Neuroprotection outlines what volunteers can expect in the NICU, including techniques that prepare them to be cuddlers. To make the guide more comprehensive, educational components were added including information about the NICU environment, common medical conditions, and the role of each NICU team member.

The creation of the guide and the knowledge the students gained while reviewing the literature reflect the benefits of being a member of NPASS. By participating in NPASS, students felt that they gained a basic understanding of the support infants require in the NICU. An NPASS member expressed, "I am grateful for this experience as it has opened the door to a setting that I knew little about and provided me with practical knowledge I can use as I enter the occupational therapy field".

Developing a NICU Cuddler Guide to Support Neuroprotection led students to discover the growing evidence for cuddling and its impact on development. For example, cuddling is shown to promote growth and weight gain, improve sleep, and decrease stress and crying [2-4]. For access to A NICU Cuddler Guide to Support Neuroprotection, please visit NPA's webpage http://www. nationalperinatal.org. This handout is available to health care practitioners as well as concerned parents who seek more information about their baby's stay in the NICU [5].

We believe there are substantial benefits of creating innovative organizations such as NPASS, which provides students with opportunities in a specialized area of practice. This is especially true for the OT profession where therapists provide services to populations across ages and settings. NPASS truly nurtures the desires of students and connects them with the resources to reach their goals. As one NPASS member remarked, "When observing in the NICU, seeing the babies and their families in this vulnerable state allowed me to fall in love with how occupational therapists can help serve this particular population with hopes that I get to work in this setting".

\section{References}

1. National Perinatal Association. 2020.

2. Harvard Medical School Teaching Hospital. The Newborn Cuddling Program.

3. Hilton L. Hugging is healing for NICU babies. Contemporary Pediatrics. 2018. 
4. Margaritoff M. Opioid addiction is so pervasive that U.S. hospitals need baby

5. NICU C.A.R.E.S. For Families. (n.d.). The Newborn cuddling program. cuddlers' to help newborns in withdrawal. 2019. 